\title{
CCSEM: a fast and reliable tool for diamond prospecting
}

\author{
Nynke Keulen ${ }^{1}$, Mark T. Hutchison ${ }^{1}$, Dirk Frei ${ }^{1}$ and Troels Nielsen ${ }^{1}$ \\ ${ }^{1}$ Geological Survey of Denmark and Greenland (GEUS), Øster Voldgade 10, 1350 Copenhagen K, Denmark, \\ ntk@geus.dk
}

\section{Introduction}

The elemental compositions of megacrystal and xenocrystal phases within kimberlitic rocks are used as an important diamond exploration tool. Classification schemes have been devised where fields of major and minor element compositions present a defined probability that the phases in question have crystallised under conditions where diamond is stable. For example, the relationships between $\mathrm{Cr}, \mathrm{Ca}$ and $\mathrm{Mn}$ contents of pyrope garnets and the $\mathrm{Cr}, \mathrm{Ca}$ and $\mathrm{Na}$ content of eclogitic garnets define such probability fields (Grütter et al., 2004). Other minerals which are routinely used in this way are ilmenites, where $\mathrm{Ni}, \mathrm{Mg}$ and $\mathrm{Cr}$ contents are important (Mitchell, 1995; Wyatt et al., 2004) and diopside where the abundance of Cr has been demonstrated to be pressure dependent (Nimis and Taylor, 2000)

The analysis of these macrocrysts is commonly performed by measuring the concentration of approximately ten to fifteen oxides using an electron microprobe. This is a precise method yet it is rather time-intensive in terms of set-up and analysis acquisition. We present CCSEM (Computer-Controlled Scanning Electron Microscopy) as a faster method to measure the composition of the macrocryst minerals and we compare the results to electron microprobe analyses in order to investigate the quality of the data. CCSEM combines the advantages of energy dispersive X-ray spectrometry (EDX) with those of digital image analysis on back scattered electron (BSE) micrographs for the automated measurements on hundreds or thousands of single grains.

\section{Sample description}

The mineral grains used in this study are indicator minerals from the Garnet Lake, Greenland, kimberlite body, where EMP compositional data have previously been published in Hutchison (2005). Garnet Lake is known to be an abundant source of diamonds. A series of hand-picked macrocrysts of ilmenite, pyrope, and olivine, were mounted in an epoxy resin. After polishing and carbon-coating, the samples were loaded into the electron microprobe (EMP) and the scanning electron microscope (SEM).

\section{Analytical Methods}

EMP analyses were carried out using the wavelengthdispersive X-ray detection systems of the JEOL 8200 Superprobe electron microprobes at the University of Copenhagen, Denmark and the University of Lausanne, Switzerland.

CCSEM analyses were performed at the Geological Survey of Denmark and Greenland (GEUS). Analyses were performed on a Philips XL40 ESEM, equipped with two EDX detectors; a Pioneer Voyager 2.7 10 $\mathrm{mm}^{2}$ window and a Thermo Nanotrace $30 \mathrm{~mm}^{2}$ window. For the analyses, the Noran Thermofisher NSS software was used combined with an in-house developed chemical re-calculation scheme and mineral database at GEUS. In the SEM, the grains appear as white and grey minerals in a black matrix (epoxy). The grey-level threshold function of the CCSEM software is able to separate individual grains from the matrix and to measure their chemical composition (for up to 90 elements), 2D-grain size and grain morphology as grain-by-grain measurements and as a bulk rock analysis. Details of this method are described by Frei et al. (2005), Bernstein et al. (2008) and Keulen et al. (2008).

Apart from point analyses, whole grain-surface compositional scans of each individual grain can be made. In this way minor compositional variations within single grains can be taken into account. The software allows the user to define a grid of minerals within which all the grains can be measured automatically. Depending on the settings for the counting intensity (e.g. maximum. 50000 counts/sec on both detectors as used in this study) and for the acquisition time per grain (e.g. 5000 counts at maximum full scale), a sample of 200 grains can be measured in 1-3 hours, with less than half an hour of operator time. The validity of the CCSEM analyses is discussed in Keulen et al., 2008. The error in the precision of the measurements is approx. $1-2 \%$ for major elements and $4-8 \%$ for minor elements under the indicated conditions. Trace elements $(<0.2 \mathrm{wt} \%)$ have relatively high errors (ca. 30\%) and can better be accessed with e.g. XRF or EMP measurements. 


\section{Results}

Garnet

To test the accuracy of the CCSEM measurements, the data were compared to EMP analyses on the same set of garnet grains. Figure 1 shows the reproducibility of the EMP analyses for the chromium and calcium concentration in garnets. The reproducibly of the EMP data by the CCSEM is good: the statistical correlation for the grains measured with both methods is 0.7 . This Figure was drawn using the classification scheme of Grütter et al. (2004), which concentrates on the minor elements $\mathrm{Cr}, \mathrm{Ca}, \mathrm{Na}$, Ti of eclogitic garnets and pyropes to differentiate eight kinds of garnets. $91 \%$ of the garnets plot in the same mineral grain field after classification based on the CCSEM and EMP chemical data. A miss-matching of the classification mainly arises close to field boundaries, e.g. for the cluster of G3-G4 garnets in the bottom centre of Figure 1. The largest problems with the Grütter classification are observed for the sub-classification of fields G3, G4 and G5. Here a threshold value of $0.07 \mathrm{wt} \%$ of $\mathrm{Na}_{2} \mathrm{O}$ distinguishes potentially diamond bearing garnets from other garnets, which show a lower likelihood for passing through the diamond window. In the EDXspectrum the peaks for the very light elements $\mathrm{Na}$ and $\mathrm{Mg}$ display a partial overlap. Trace amounts of $\mathrm{Na}$ in grains with abundant $\mathrm{Mg}$ are therefore not measured with a reliable precision, even with increased counting times.

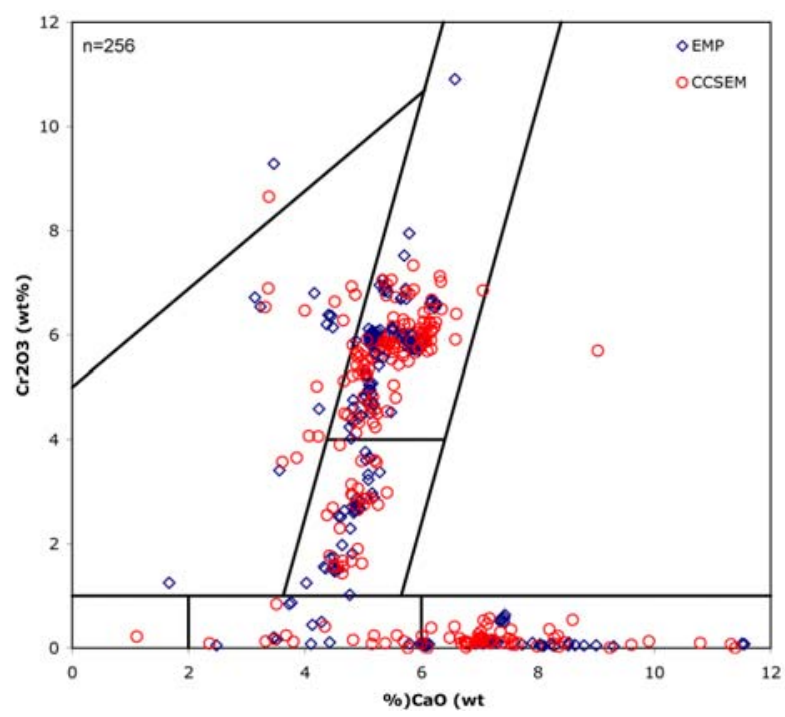

Figure 1: Comparison between CCSEM and EMP for $\mathrm{CaO}$ and $\mathrm{Cr} 2 \mathrm{O} 3$ in pyrope and eclogitic garnets. (Redrawn after Grütter et al., 2004.)

\section{Ilmenite}

Wyatt et al. (2004) showed that the ratio between $\mathrm{MgO}$ and $\mathrm{TiO}_{2}$ in ilmenites can be used as an indicator of a kimberlitic association of these minerals. Ilmenites associated with kimberlites plot at the high $\mathrm{MgO}$ side of the solid line in Figure 2. We compared the performance of CCSEM to analyses on the same grains measured with the EMP. All but one of the grains plot within the kimberlite field; thus CCSEM can be used to identify this field correctly. The CCSEM-data show a slightly larger scatter than the EMP data, but have the same average values for $\mathrm{TiO}_{2}$ and $\mathrm{MgO}$.

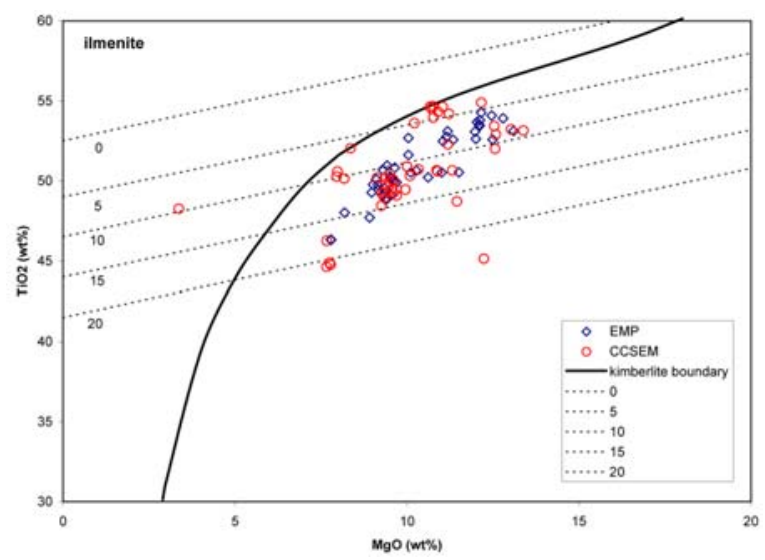

Figure 2: Comparison between CCSEM and EMP for $\mathrm{TiO}_{2}$ and $\mathrm{MgO}$ in ilmenite. Dashed diagonal lines indicate lines of equal $\mathrm{Fe}_{2} \mathrm{O}_{3}$. (Redrawn after Wyatt et al., 2004)

Figure 3 shows the relation between $\mathrm{Cr}_{2} \mathrm{O}_{3}, \mathrm{MnO}$ and $\mathrm{MgO}$ in ilmenite. The minor elements $\mathrm{Cr}, \mathrm{Mn}$ and $\mathrm{Mg}$ can be measured with a good accuracy in ilmenites.

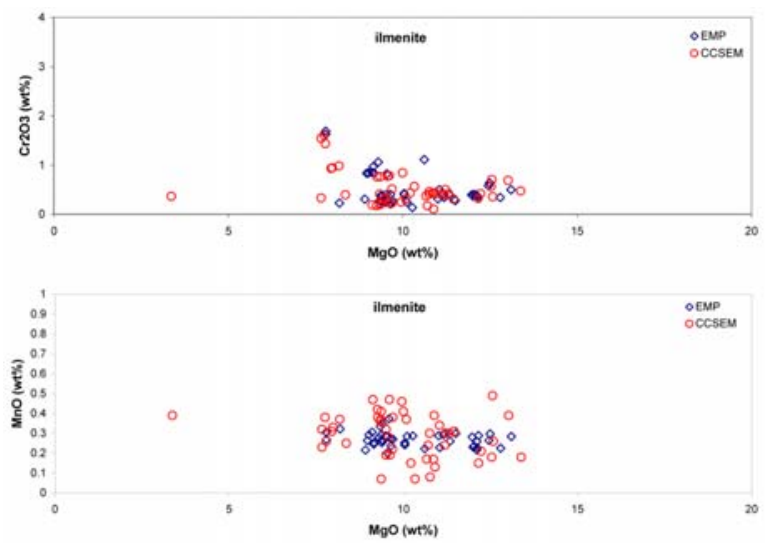

Figure 3: Comparison between CCSEM and EMP for $\mathrm{Cr} 2 \mathrm{O} 3$ and $\mathrm{MnO}$ in Mg-rich ilmenites grains.

\section{Olivine}

Chromium and Nickel are used as indicator minerals for kimberlitic rocks (Mitchell, 2000). Here the concentration of $\mathrm{Cr}_{2} \mathrm{O}_{3}$ in fayalites is show (Figure 4).

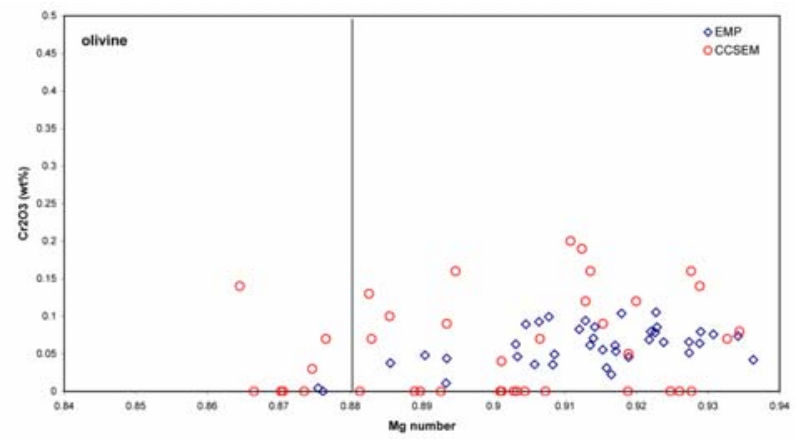

Figure 4: Comparison between CCSEM and EMP for $\mathrm{Cr}_{2} \mathrm{O}_{3}$ in fayalite. 
Most of the measured olivine grains plot within the kimberlite field, which lies to the right of $\mathrm{Fa}_{88}$. Chromium is only present in very small quantities, but is represented with a correct average, but a larger scatter compared to EMP measurements. The error in the $\mathrm{Cr}_{2} \mathrm{O}_{3}$ measurements is $6 \%$; in the $\mathrm{Mg}$-number $1.2 \%$. The concentration of Chromium in olivine is on the same level as $\mathrm{Na}$ in the pyropes and eclogitic garnets, but chromium in olivine is much better resolved in the EDX spectrum than $\mathrm{Na}$ in pyropes.

\section{Discussion}

The chosen measurement conditions greatly exceed conventional EDX measurement conditions in terms of the total acquired analytical counts per mineral. These improved measurement conditions were made possible by the application of a second EDX detector, by the automation of the measuring procedure, and by the coupling of the measured chemistry to our mineral database. In this way a much lower error in the precision of the measurements compared to conventional EDX analyses was achieved. The measurements on the discussed indicator minerals demonstrate a good reproduction of the EMP analyses with the CCSEM. We are confident that this validity of the data can also be achieved for other kimberlitic minerals and mantle indicator minerals, such as pyroxene, chromite, phlogopite and apatite.

CCSEM provides a significant cost advantage through reduction in machine-time and in particular, man-hours compared to EMP. CCSEM is only less suitable to measurement of small fractions of $\mathrm{Na}$ in pyrope grains compared to EMP. In this case, CCSEM can still function as a method to investigate the potential of kimberlite samples for further study. However, the large majority of the measured indicator grains presented plotted in the same discriminatory field, irrespective of the method used. CCSEM is able to measure major and minor element concentrations in indicator minerals almost the same precision as the EMP. As a faster, cheaper, alternative to microprobe measurements on indicator minerals CCSEM is therefore demonstrated to be a valid prospecting tool.

\section{Acknowledgements}

Hudson Resources Inc. are acknowledged for provision of Garnet Lake indicator minerals for technique developement.

\section{References}

Bernstein, S., Frei, D., McLimans, R., Knudsen, C. Vasudev, V.N. 2008. Application of CCSEM to heavy mineral deposits: Source of high-Ti ilmenite sand deposits of South Kerala beaches, SW India. Journal of Geochemical Exploration, 96(1), 25-42.

Frei, D., Knudsen, C., McLimans, R.K., Bernstein, S., 2005. Fully automated analysis of the chemical and physical properties of individual mineral species in heavy mineral sands by Computer Controlled Scanning Electron Microscopy (CCSEM). Proceedings of 2005 Heavy Mineral Conference, 103-108.

Grütter, H. S., Gurney, J.J., Menzies, A.H., Winter, F. 2004. An updated classification scheme for mantle-derived garnet, for use by diamond explorers. Lithos, 77, 841-857.

Hutchison, M.T., 2005. Diamondiferous kimberlites from the Garnet Lake area, west Greenland: exploration methodologies and petrochemistry. Danmarks og Grønlands Undersøgelse Rapport, 2005/68, 33-42

Hutchison, M.T., Heaman, L.M., Chemical and physical characteristics of diamonds from the Garnet Lake kimberlite, Sarfartoq, West Greenland: an association with carbonatitic magmatism. Under review, Canad. Mineral.

Keulen, N., Frei, D., Bernstein, S., Hutchison, M.T., Knudsen C., \& Jensen L. 2008. Fully automated analysis of grain chemistry, size and morphology by CCSEM: examples from cement production and diamond exploration. Geological Survey of Denmark and Greenland Bulletin, 15, 93-96.

Mitchell, R.H., 1995. Kimberlites, Orangeites and Related Rocks. Plenum, New York

Nimis, P. and Taylor, W.R. 2000. Single clinopyroxene thermobrometry for garnet peridotites: Part 1. Calibration and testing of a Cr-in Cpx barometer and an enstatite-in-Cpx thermometer. Contributions to Mineralogy and Petrology 139, 541-554.

Wyatt, B.A., Baumgartner, M., Anckar, E., Grütter, H. 2004. Compositional classification of "kimberlitic" and "non-kimberlitic" ilmenite. Lithos, 77, 819-840. 